\title{
Atomic Resolution Microscopy of Clathrate-I Type Borosilicides
}

\author{
Reiner Ramlau ${ }^{1}$, Walter Jung ${ }^{1}$ and Yuri Grin ${ }^{1}$ \\ ${ }^{1 .}$ Max-Planck-Institut für Chemische Physik fester Stoffe, Dresden, Germany.
}

Until now the ternary $\mathrm{K}_{7} \mathrm{~B}_{7} \mathrm{Si}_{39}$ [1] and the quaternary $\mathrm{K}_{2.73} \mathrm{Rb}_{3.93} \mathrm{~B}_{6.78} \mathrm{Si}_{39.5}$ [2] are the only known borosilicides with clathrate-I structure ( $c P 54)$. Both compounds crystallize in space group Pm-3n with $a=0.9952 \mathrm{~nm}$ and $a=0.9969 \mathrm{~nm}$, respectively. A framework of 46 tetrahedrally coordinated "host" atoms per unit cell form two kinds of cage, small 20-membered (dodecahedral) and large 24-membered (tetrakaidecahedral) ones. There are 2 small cages and 6 large cages per unit cell - and per formula unit. The closely packed "host" cages are occupied by the "guest" atoms: here K and Rb. Substitution of Si "host" atoms by B results in a considerable contraction of the lattice parameter compared with the corresponding binary silicide $\mathrm{K}_{8-x} \mathrm{Si}_{46}(x<1)$ [3]. This contraction might favor smaller guest ions to be embedded into the cages. Therefore, Si clathrates with B in the host framework provide opportunities for the synthesis of narrow band gap semiconductors. Writing the quaternary borosilicide somewhat simplified as $(\mathrm{K}, \mathrm{Rb})_{7} \mathrm{~B}_{7} \mathrm{Si}_{39}$ clarifies the relationship to its ternary sister. The disproportion between the number of guest atoms available and the number of cages is evident for both compounds. In the case of $\mathrm{K}_{7} \mathrm{~B}_{7} \mathrm{Si}_{39}$ it is deduced from $\mathrm{x}$-ray data [1] and chemical considerations that the large cages are completely filled ( $6 d$ site) and the small cages are statistically half occupied ( $2 a$ site). In the case of $\mathrm{K}_{2.73} \mathrm{Rb}_{3.93} \mathrm{~B}_{6.78} \mathrm{Si}_{39.5}$, however, the large cages $(6 d)$ are expected to be filled by $\mathrm{Rb}$ and $\mathrm{K}$. For the small cages $(2 a)$ only $0.66 \mathrm{~K}$ atoms per unit cell remain: that means only on third of these cages should be occupied. On the other hand, $\mathrm{Si}$ and $\mathrm{B}$ share the $16 i$ site of the host lattice statistically in a 9:7 ratio. Ordering of $\mathrm{Rb}$ at $6 d$ (only for the quaternary compound!), of $\mathrm{K}$ at $2 a$ and of $\mathrm{B}$ at $16 i$ could be neither proven nor excluded by x-ray investigation.

The Dresden "Grand ARM" is a double- $C_{S}$-corrected JEOL ARM 300F [4]. With a STEM resolution of $50 \mathrm{pm}$ and a TEM resolution of 50 to $70 \mathrm{pm}$ (depending on the criterion applied) it is the instrument of choice to investigate the clathrate-I borosilicides more closely. All the more so because inter-atomic spacings (K-Si, $\mathrm{Rb}-\mathrm{Si}, \mathrm{Si}-\mathrm{Si}$ ) go down to $47 \mathrm{pm}$ and $43 \mathrm{pm}$ in [100] and [111] projections, respectively.

High-resolution STEM does not provide indication of any pronounced ordering, except for the ordering of $\mathrm{K}$ in some domains of the ternary compound. The term "ordered" is used here to denote long-range order, whereas "disordered" effectively still includes some short-range order between the host and guest substructures. They do not exist independently of each other. The occupation of host sites by B changes the size of the cages involved and leads to consequences for the occupation of guest sites. Furthermore, a guest atom may be displaced from the cage center. All this holds for both ordered and disordered arrangements and leads to a wide variety of real structure phenomena [5].

\section{References:}

[1] W Jung et al, Angew. Chem. Int. Ed. 46 (2007) p. 6725.

[2] W Jung, Y Grin and M Baitinger, $6^{\text {th }}$ Intern. Conf. Inorg. Materials, Dresden (2008) p. 2-70.

[3] B Böhme et al, J. Am. Chem. Soc.129 (2007) p. 5348.

[4] R Ramlau, Y Grin and H Sawada, JEOL News 51 (2016) p.2.

[5] Advice and support by Dr. Hidetaka Sawada, JEOL UK Ltd., is gratefully acknowledged. 

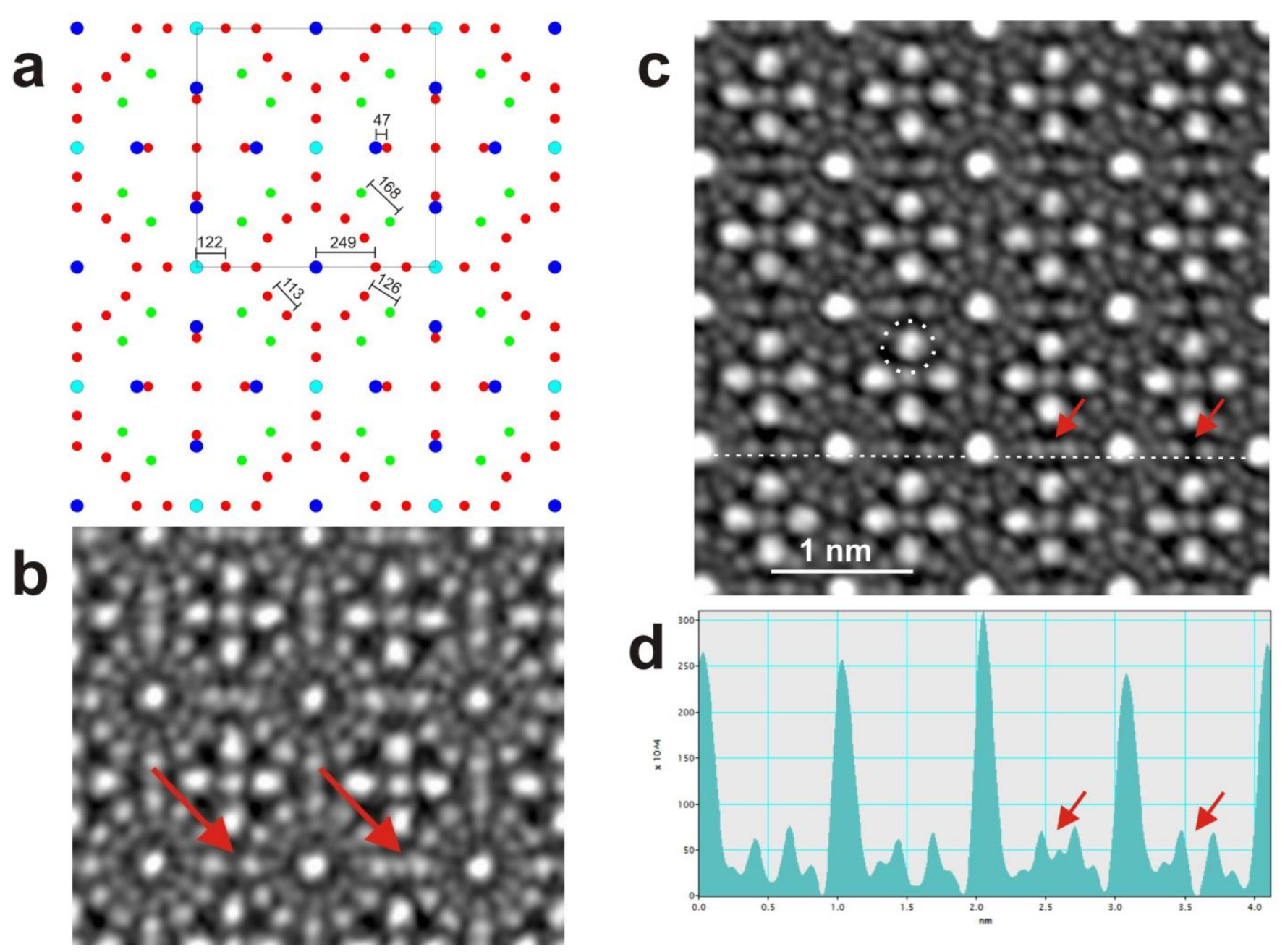

Figure 1.

a) Projected structure of $\mathrm{K}_{7} \mathrm{~B}_{7} \mathrm{Si}_{39}$ and $\mathrm{K}_{2.73} \mathrm{Rb}_{3.93} \mathrm{~B}_{6.78} \mathrm{Si}_{39.5}$, resp., in [100] direction. Unit cell and selected atomic interspaces in $\mathrm{pm}$ are indicated. Green: $\mathrm{Si} / \mathrm{B}$ at $16 i$, red: $\mathrm{Si}$ at $24 k$ and $6 c$, light-blue: $\mathrm{K}$ at $2 a$ (center of the small, dodecahedral cage) and dark-blue: $\mathrm{K} / \mathrm{Rb}$ at $6 d$ (center of the large, tetrakaidecahedral cage). In this projection the interspaces between the $6 d$ and the $24 k$ sites, e.g. K and $\mathrm{Si}$, are as small as $47 \mathrm{pm}$ - making the borosilicides good test specimens for (S)TEM resolution.

b) HAADF-STEM of $\mathrm{K}_{7} \mathrm{~B}_{7} \mathrm{Si}_{39}$ in [100]. Red arrows indicate $\mathrm{K}$ at $2 a$. Different occupancies, between zero and full are revealed, as well as great general disorder and missing translational periodicity.

c) HAADF-STEM of $\mathrm{K}_{2.73} \mathrm{Rb}_{3.93} \mathrm{~B}_{6.78} \mathrm{Si}_{39.5}$. Red arrows indicate $\mathrm{K}$ at $2 a$; the occupancy seems to be lower than expected from x-ray results (33\%). Quantitative analysis is hampered by the projection problem. The defect situation adds up over at least 3 unit cells $(3 \mathrm{~nm})$. The region encircled in white represents projected "pairs" of atoms $\mathrm{K}-\mathrm{Si}$ and/or $\mathrm{Rb}-\mathrm{Si}$ whose interspace is $47 \mathrm{pm}$ following to x-ray investigations. These pairs are almost resolved in the STEM images (band-pass filtered and rectified) illustrating the excellent performance of the Dresden "Grand ARM".

d) Along the dashed white line in c) an intensity profile was taken to illustrate the varying occupancy of $\mathrm{K}$ at $2 a$ more quantitatively. See the red arrows in c) and d)! 